\title{
Aviation Hazards Over the Jomsom Airport of Nepal as Revealed by Numerical Simulation of Local Flows
}

\author{
Ram P. Regmi \\ Central Department of Physics \\ Tribhuvan University, Kirtipur, Kathmandu, Nepal. \\ Email: regmi_rp@hotmail.com
}

\begin{abstract}
Jomsom Airport of Nepal is considered to be one of the world's most extreme airports. The frequency of aircraft crashing along the Kali Gandaki River Valley and over the Jomsom Airport is very high. Pre-monsoon time local flow characteristics over the Kali Gandaki Valley has been studied to understand the meteorological hazards for aviation activities along the valley and over the Jomsom Airport with the application of the WRF Modeling System initialized with NCEP meteorological, USGS 24 categories land use, and 30 second terrain data. Four days long simulation was carried out for the period of 15 May 0000 UTC to 19 May 0000 UTC, 2012 to capture the 16 May 2012 incidence of light aircraft crashing in the late morning time of the day. The study revealed that there are enough grounds to believe that the crashing of the plane resulted due to the adverse local flow system prevailing over the Jomsom Airport area during the period. The significant subsidence from the relatively strong boundary layer wind aloft, the ground level opposite wind and the low-level turbulence might have leaded the airplane to crash just after its takeoff from the runway. The local flow system over the Kali Gandaki Valley makes afternoon time flights over the Jomsom Airport almost impossible and the narrow slot of time during morning time is also not free from difficult situation.
\end{abstract}

Keywords: Flight safety, Jomsom airport, atmospheric modeling, hydraulic jump, wind shear.

\section{INTRODUCTION}

The Jomsom Airport resides at an elevation of $2682 \mathrm{~m}$ above the mean sea level in the world's deepest gorge of Kali Gandaki River. The river gorge becomes as much as $5000 \mathrm{~m}$ deep while crossing the Annapurna and Dhaulagiri Himalayas. The air route to Jomsom Airport enters into the Kali Gandaki River gorge at Ghasa and follows the path along Lete, Tukuche, Marpha, and Jomsom. The gorge extends further north along Kagbeni, Chuksang, Chile, Lo Manthang and finally exiting into the Plateau of Tibet (Fig. 1).

The axis of the valley orients southeasterly at Ghasa and few kilometers upstream to Lete and then bends taking southwesterly orientation up to Lo Manthan and beyond. The valley ascends steeply from Ghasa to Lete but it ascends more gradual from Lete to Lo Manthang. The air route to approach Jomsom Airport captures an exceptional topographic constrains for aviation activities as one has to follow all along and deep into the winding gorge of Kali Gandaki River. The local flows that prevail in such a complex river gorge can be expected to be extremely hazardous for aviation, particularly, for small aircrafts. Indeed, Jomsom Airport is considered to be one of the most difficult airports in the world.

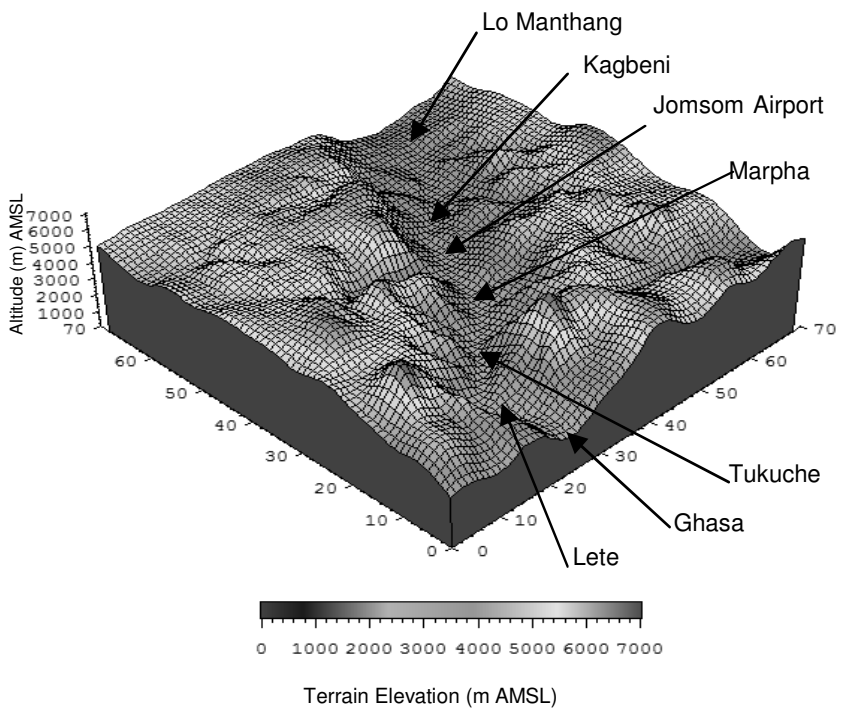

Fig. 1. Bird-Eye view of Kali Gandaki River Valley and its surroundings.

The frequency of aircrafts crashing in and around the Jomsom Airport is very high (e.g., see Figs. 2b-c). 
However, there have been no significant studies on aviation hazards attributable to characteristic local flows along the valley and over the Jomsom Airport. In this paper we will discuss the implications of local flows along gorge and over the Jomsom Airport.

Significant studies on meteorological flow characteristics over the Kali Gandaki Valley appears to begin in the late 1990s with the exploration of diurnal wind system of the valley during September and October months of 1998 using pilot balloons and surface observation at various spots along the valley (Egger $e t$ al. 2000) followed by numerical simulation of diurnal wind characteristics with the application of mesoscale meteorological model MM5 (Zängl et al. 2001).
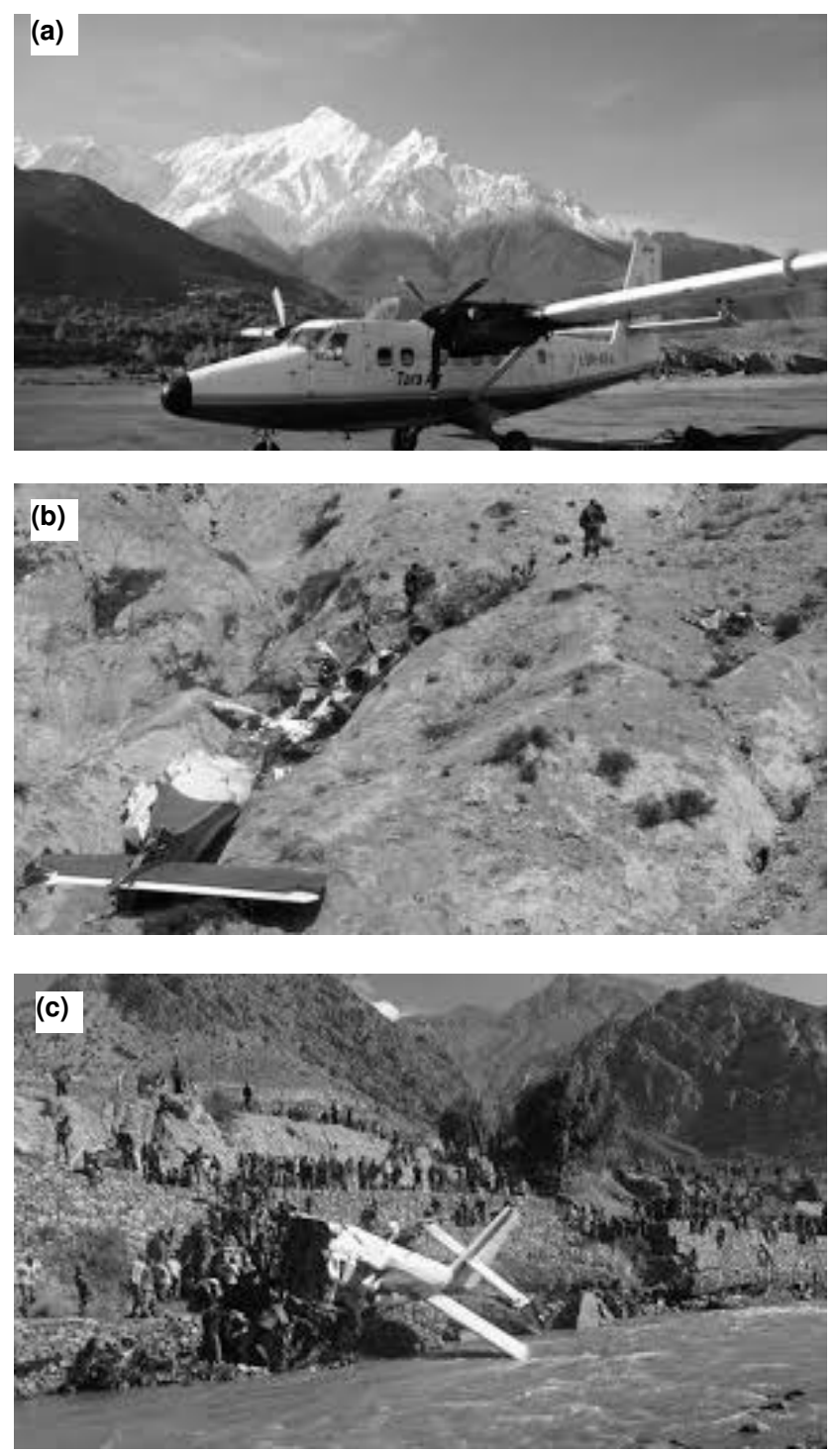

Fig. 2. A pictures of Jomsom Airport (a), recent airplane crashes in immediate vicinities of the Jomsom Airport (b) and (c).
They observed very intense upvalley winds with typical wind speed of 15-20 $\mathrm{ms}^{-1}$ during the day, particularly, in between Marpha and Tuksang and the same situation was predicted numerically. The deep upvalley inflow wind layer of 1000-2000 m depth formed along the valley that may persists up to Lo Manthang close to the Plateau of Tibet. The upvalley wind exhibited the nature of supercritical flow. The upvalley wind begins to decelerate in the late afternoon and vanishes in the late evening but only in the late night a weak drainage flow develops over the Kali Gandaki valley that may continue to flow until sunrise.

Furthermore, investigation of characteristics of atmospheric stratification over the valley was carried out with remotely piloted airplanes complemented with surface observations (Egger et al. 2002) for better understanding the flow dynamics in the valley. The vertical profiles of temperature and humidity were measured up to height of $2000 \mathrm{~m}$ above the ground during 17 February to 27 March 2001. This exploration reconfirmed the basic features of the local flow characteristics over the valley both observed and numerically predicted earlier. However, based on the new findings on nature of the turbulent layer, stratification and the inversion, they excluded the earlier versions of explanation (Zängl et al. 2001) of the strong winds in terms of hydraulic theories and proposed that the extreme acceleration of the upvalley wind over the valley results as a consequence of the flow above the neutral layer.

These studies have clearly indicated that the fundamental features of the local flows over the Kali Gandaki Valley's complex terrain can be numerically simulated with the applications of advanced mesoscale meteorological models. Based on this assertion of applicability of meteorological models, local wind fields prevailing over the valley were numerically simulated during the early monsoon season. This was not covered in the past studies. Further motivation to choose this particular period came through the recent airplane crash on 16 May 2012 at Jomsom Airport (Fig. 2c).

\section{MATERIALS AND METHODS}

The pre monsoon local flow characteristics over the Kali Gandaki valley were studied with the application of the state-of-the-art-of Weather Research and Forecasting (WRF) Modeling System (Skamarock et al. 2005). The model was initialized with NCEP 6-hourly meteorological data with a resolution of $1.0^{\circ} \times 1.0^{\circ}$. The 
simulation was carried out for the period of 15 May 0000 UTC to 19 May 0000 UTC, 2012. In this calculation we used land use of 24 categories and 30second terrain elevation data by United States Geological Survey (USGS). The domain system used in this calculation consists of a triply nested two-way interacting mesh. The coarse and the find domain include $51 \times 51 \times 34$ grid points, and horizontal grid size is 9 and $3 \mathrm{~km}$, respectively, whereas the finest domain include $70 \times 70 \times 34$ grid points with horizontal grid size is $1 \mathrm{~km}$. The model top was set at $50 \mathrm{hPa}$ and the lowest layer at $30 \mathrm{~m}$ AGL. The area coverage and terrain structure of the finest domain is shown in Fig.1.

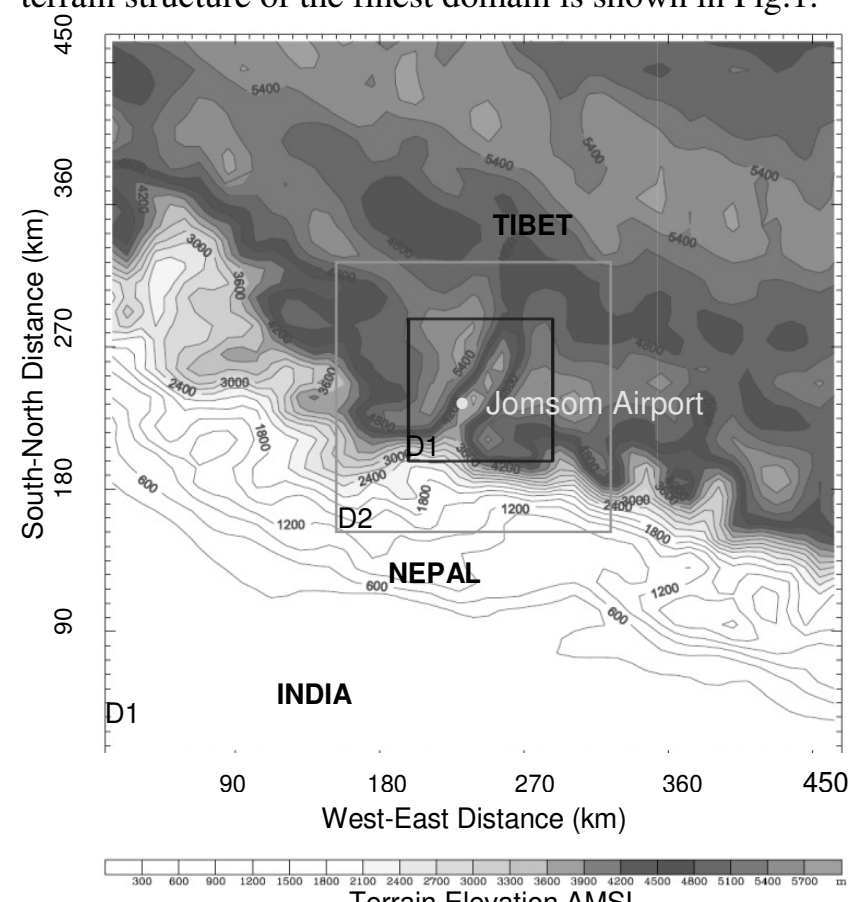

Fig. 3. Geographical coverage of calculation domains: coarse domain (D1), fine domain (D2) and the finest domain (D3). The finest domain of $70 \mathrm{~km} x 70 \mathrm{~km}$ area covers the whole Kali Gandaki Valley. The center of all the domains is set $28.86^{\circ} \mathrm{N}$ and $83.78^{\circ} \mathrm{E}$.

The center of the calculation was set close to the observation site $\left(28.86^{\circ} \mathrm{N}\right.$ and $\left.83.78^{\circ} \mathrm{E}\right)$ few kilometers upstream to the Jomsom Airport (see Fig. 3 for domain configurations and locations). The simulations were carried out using planetary boundary layer (PBL), and surface layer schemes and the NOAH land surface model (LSM), along the Dudhia short wave, RRTM long-wave radiation parameterizations.

The parameterization of scheme Lin et al. and the KainFritsch convective parameterization scheme were used for coarse domain whereas no such parameterization rationales of the model predictions were examined against the observed diurnal variation of temperature and wind speed.

\section{RESULTS}

During the four days long simulation, almost the same diurnal variations of local flows were predicted except for the snipup period of model calculation, i.e., the first 24 hours after model initialization. Thus, the results of the first 24 hours simulation were not taken into considerations. Among the later three days of calculation, we preliminary consider the diurnal variation of local flows for the day of 16 May 2012 for detail discussions, as this was the day in which an aircraft of Nepal Airlines was crashed (see Fig. 2c).

\section{Rationale of numerical simulation}

A desired comparison of model predictions against the observation data could not be made due to the unavailability of sufficient observation data. Nevertheless, very good agreements have been achieved in between the observed and calculated wind speed, wind direction, and the air temperature (see Fig. 4). The little difference that can be seen in between the observation and calculation can be attributed to the differences in between the heights of observation and calculation level. Moreover, model calculates an average of $1 \mathrm{~km}^{2}$ area whereas the measurement gives pinpoint results. Thus, there are enough grounds to believe that present simulation has captured the very nitty-gritty of local flow fields along the Kali Gandaki Valley and over the Jomsom Airport during the calculation period.
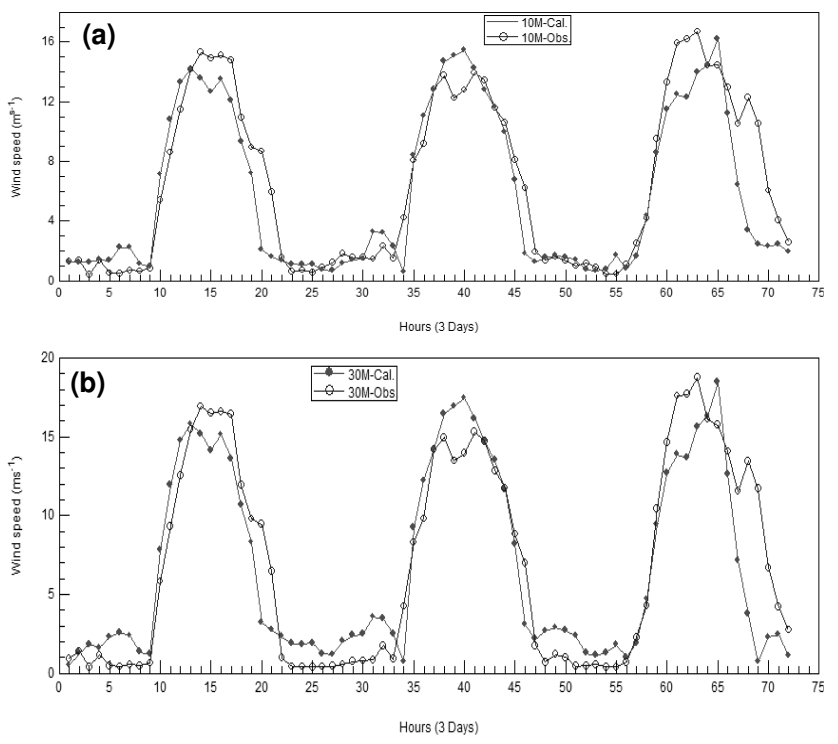

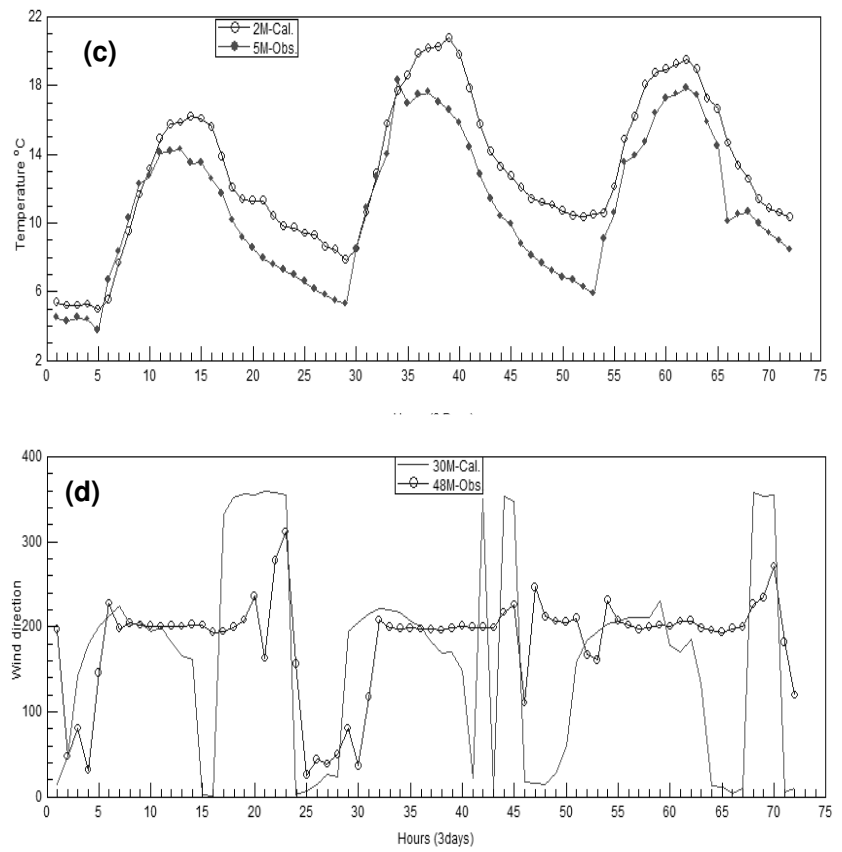

Fig. 4. Comparison of observed and the nearest grid point calculated wind speed at $10 \mathrm{~m}$ (a) and $30 \mathrm{~m}$ (b), temperature observed at $5 \mathrm{~m}$ and calculated at $2 \mathrm{~m}$ (c), and the wind direction observed at $48 \mathrm{~m}$ and calculated at $30 \mathrm{~m}$ (d) above the surface.

The little difference that is seen in between the observation and calculation can be attributed to the differences in between the heights of observation and calculation level. Moreover, model calculates an average of $1 \mathrm{~km}^{2}$ area whereas the measurement gives a pinpoint result. Thus, there are enough grounds to believe that present simulation has captured the very nitty-gritty of local flow fields along the Kali Gandaki Valley and over the Jomsom Airport during the calculation period.

\section{Spatial and temporal distribution of near surface wind}

Numerical predictions in consistent with the observed diurnal variation of winds show that there is an unprecedented asymmetry in the intensities of daytime upvalley and nighttime downvalley wind speeds along the Kali Gandaki Valley. During the late night until early morning, the near surface wind appears very weak from Marpha to Lo Manthang area but relatively strong drainage wind prevails over Marpha down to Ghasa area (Figs. 5a-b). Interestingly, small pocket area around the Kagbeni, typically, experiences drainage flows during the period but this drainage flow vanishes before reaching Jomsom area a few kilometers downstream. However, high Himalayan surfaces surrounding the valley appear very windy during the night and morning times. The flow situation remains nearly the same with minor changes until 0845 LST (Fig. 5c). Beyond 0845 LST the drainage flow quickly ceases and by 0945 LST, the whole valley floor from Ghasa up to Lo Manthan becomes calm and then the valley immediately develops strong upvalley wind that progressively moves upstream of the valley (Fig. 5d).

By 1145 LST, a storm like wind prevails between Tukuche and Chuksang areas (Fig. 5e) that may reach beyond Lo Manthang and up into the Plateau of Tibet by 1245LST (Fig. 5f). The wind speed predicted and measured close to Chuksang (Fig. 4a-b) appears to be around $16 \mathrm{~ms}^{-1}$ but more than $19 \mathrm{~ms}^{-1}$ over Jomsom and Kagbeni areas (Fig. 5g). The wind speed appears to be maximum in between 1245 to 1645 LST. Importantly, the intensity of the near surface valley wind appears very weak or calm in between Ghasa to Tukuche area when peak wind speed prevails over the areas upstream to Tukuche (Fig. 5g). After 1645 LST, the near surface wind over the valley above Tukuche gradually begins to decrease and the whole valley from Ghasa to Lo Manthan and above becomes calm (Figs. 5h-i) and a gentle drainage wind starts to flow along the valley and eventually returns to the situation described earlier for early morning time.

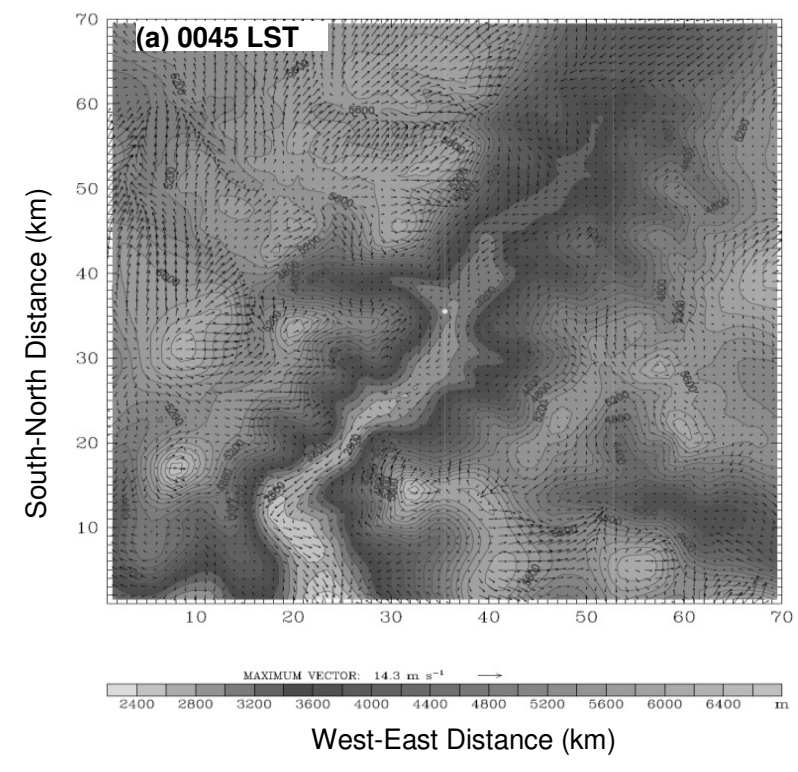




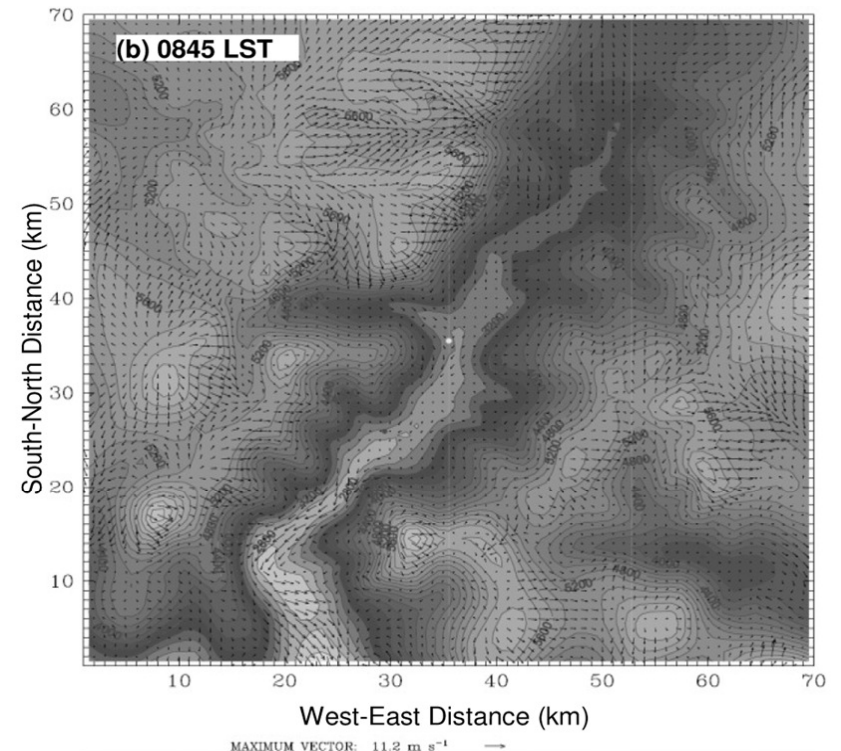

\begin{tabular}{|c|c|c|c|c|c|c|c|c|c|c|}
\hline 2400 & 2800 & 3200 & 3600 & 4000 & 4400 & 4800 & 5200 & 5600 & 6000 & 6400
\end{tabular}

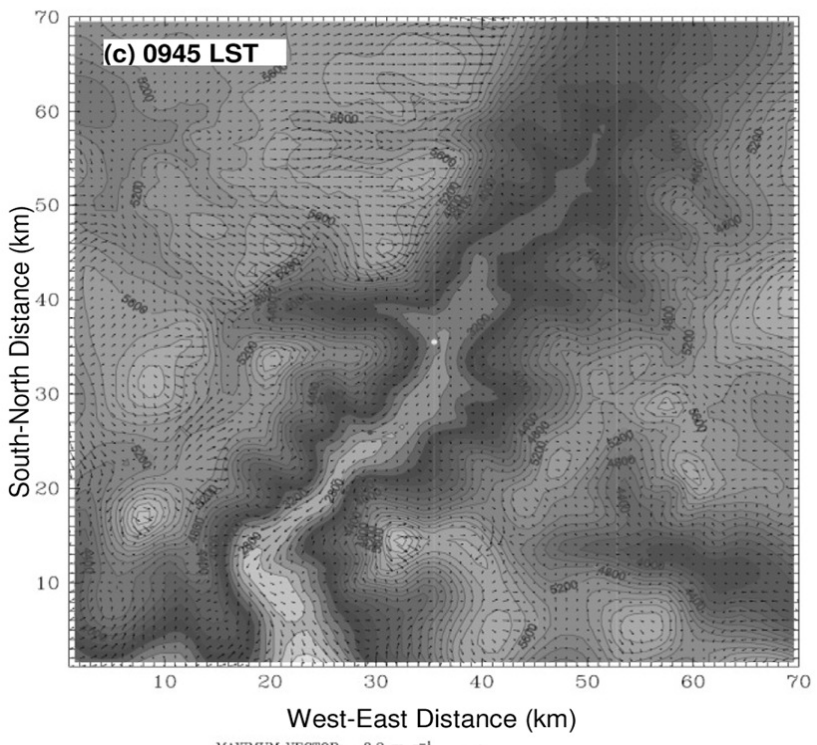

\begin{tabular}{|c|c|c|c|c|c|c|c|c|c|c|}
\hline $\mid$ & $\mid$ & MAXIMUM VECTOR: & $8.2 \mathrm{~m} \mathrm{~s}^{-1}$ & - & & $\mid$ & $\mid$ & $\mid$ & $\mid$ & $\mid$ \\
\hline 2400 & 2800 & 3200 & 3600 & 4000 & 4400 & 4800 & 5200 & 5600 & 6000 & 6400
\end{tabular}

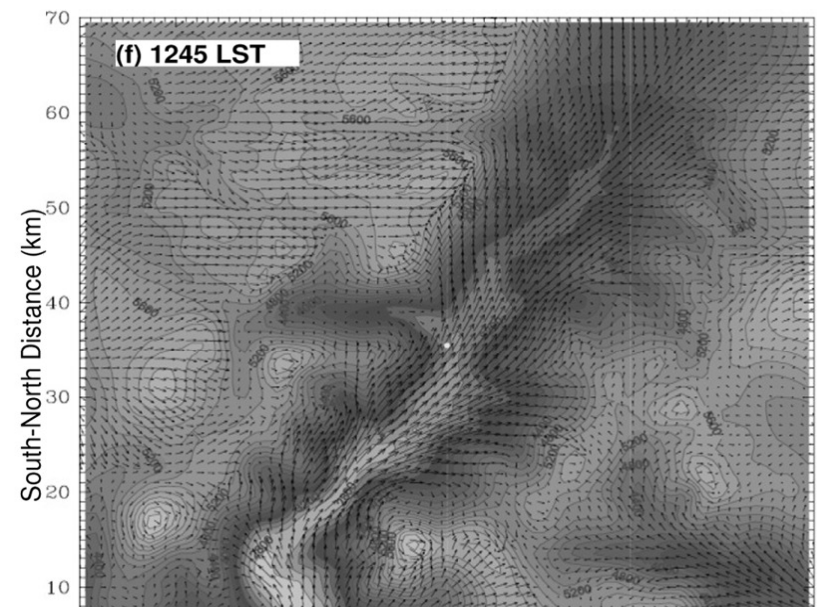

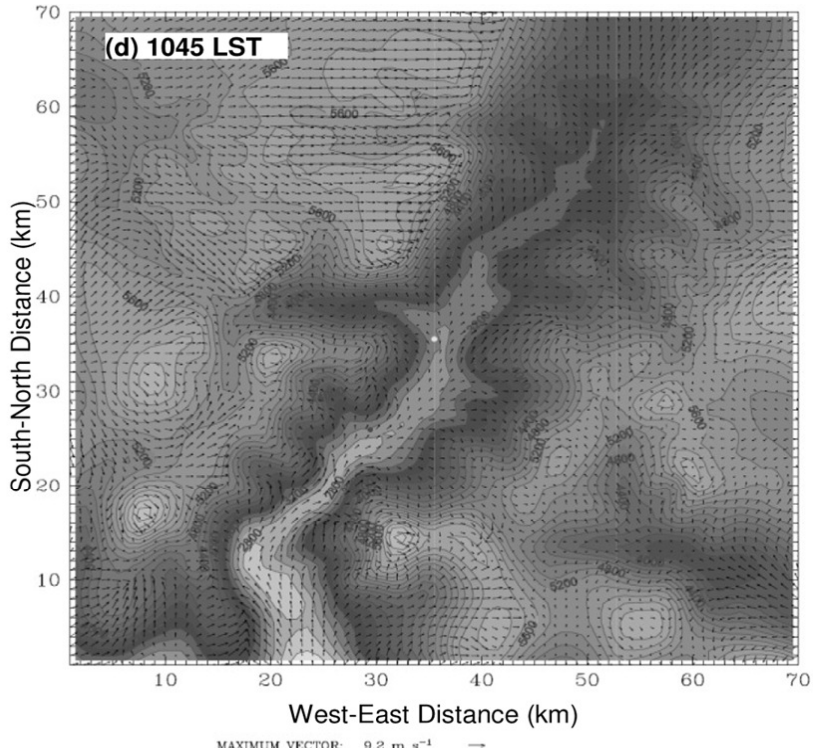

\begin{tabular}{|c|c|c|c|c|c|c|c|c|c|c|c|}
\hline $\mid$ & $\mid$ & $\mid$ & $\mid$ & $\mid$ & $\mid$ & $\mid$ & $\mid$ & $\mid$ \\
\hline 2400 & 2800 & 3200 & 3600 & 4000 & 4400 & 4800 & 5200 & 5600 & 6000 & 6400 & \\
\hline
\end{tabular}
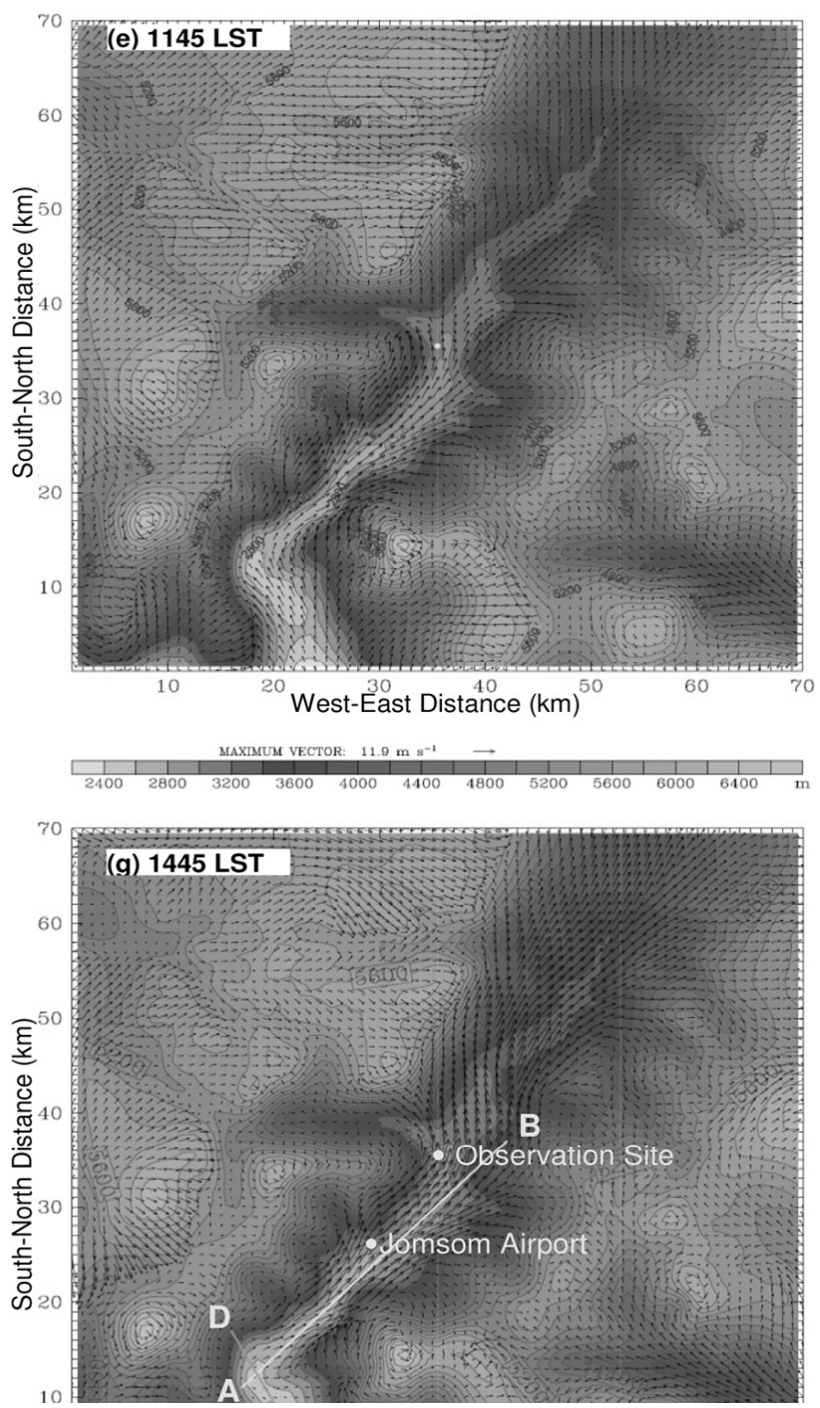

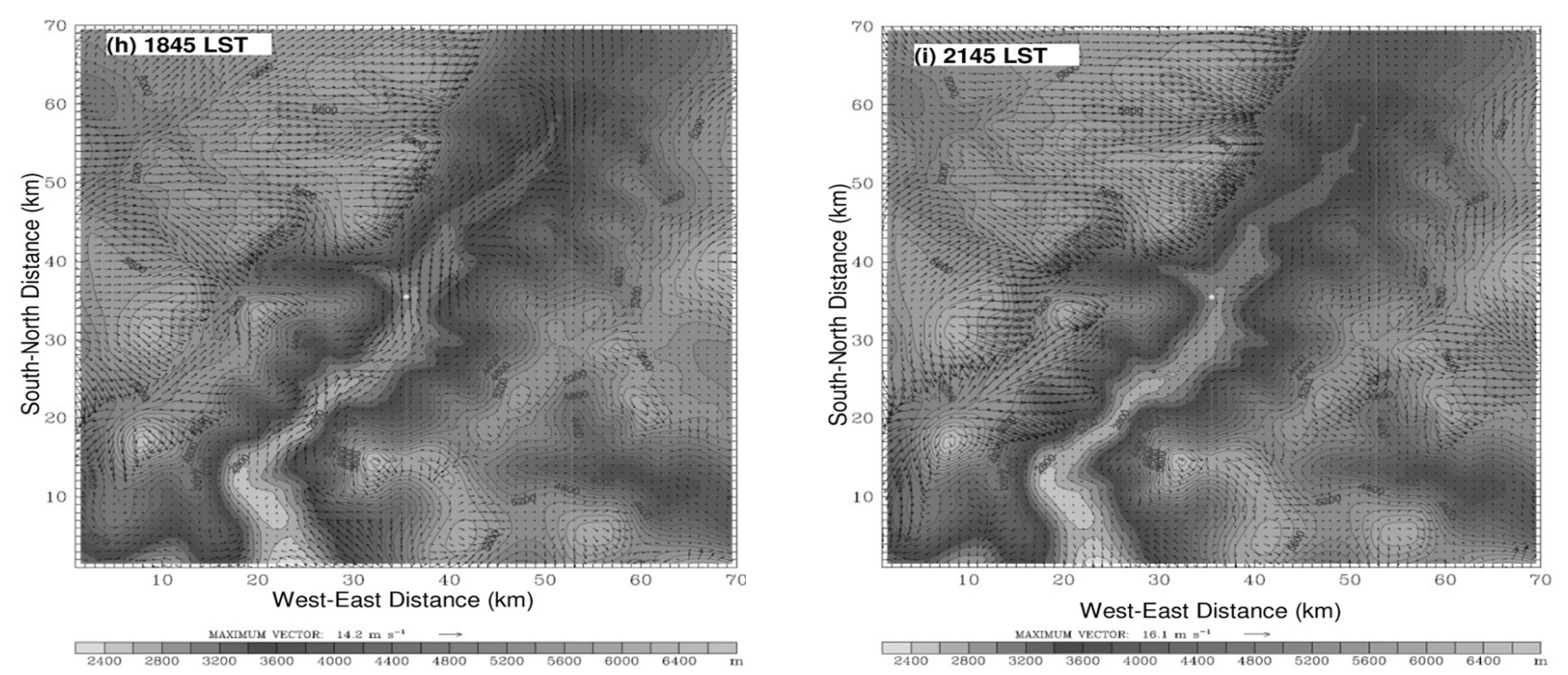

Fig. 5. Diurnal distribution of near surface wind over the Kali Gandaki Valley and Jomsom Airport on 16 May 2012.

\section{Vertical structure of flow fields}

Fig. 6 shows the vertical structure of the horizontal and vertical winds and the potential temperature distribution early morning times (e.g., see Fig. 6a) it can be said that a moderately gentle drainage flow of about $300 \mathrm{~m}$ in deep may prevails over the Kali Gandaki Valley. The atmosphere above this layer and up to $4 \mathrm{~km}$ above the mean sea level appears stagnated. However, a pronounced wind layer appears to flow aloft the stagnated layer in the direction opposite to the drainage flow. This particular local flow situation appears to continue more or less the same until 0545 LST (Fig. 6b). As the morning progresses, the stagnated layer above

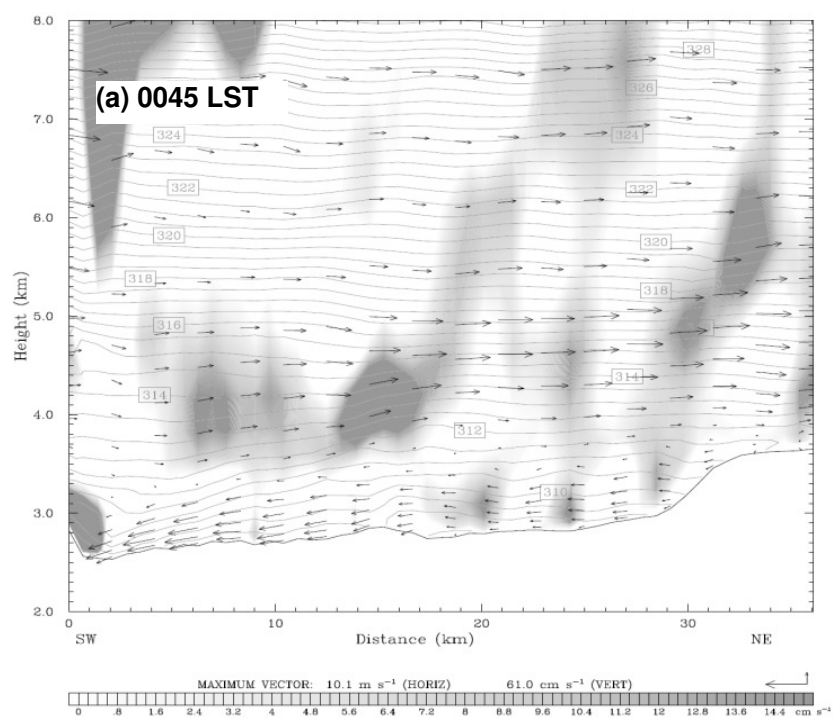

along the line A-B (Fig. 5g). Examining the series of hourly predicted cross sectional distribution of horizontal wind during the late night and

the drainage flow squeezes and the two wind layers tend to couple up. A weak subsidence from bottom level of the upper wind layer tends to feed the drainage flow after 0745 LST (Fig. 6c). The drainage flow disappears at 0945 LST and an appreciable subsidence from the upper wind layer down to the surface (Fig. 6d) that makes the weak downslope flow over the valley in between Marpha and Lo Manthang. This subsidence wind appears to be quickly replaced by strong and deep upvalley wind (Fig. 6e).

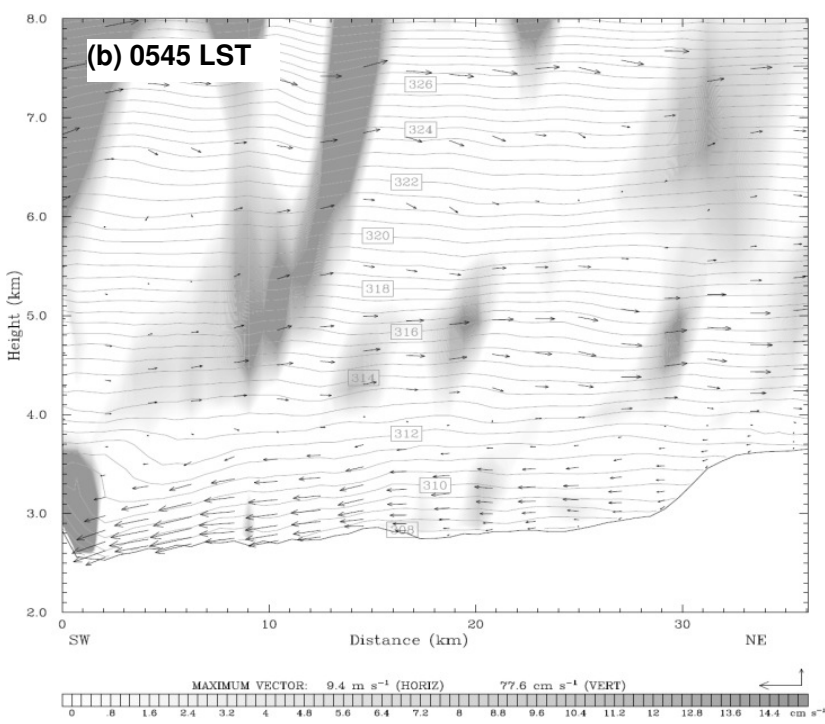




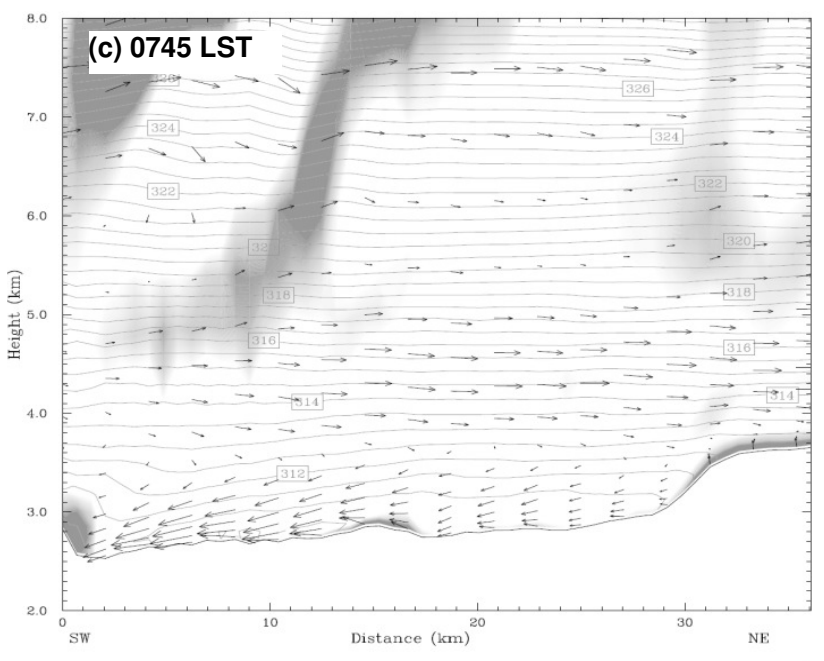

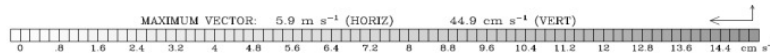

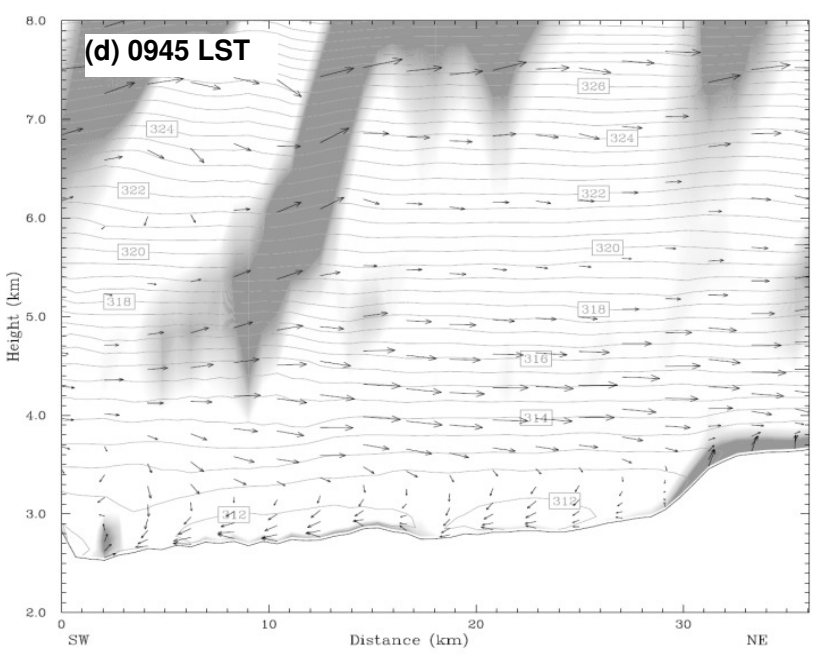

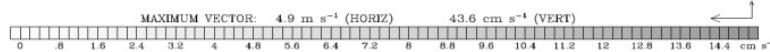

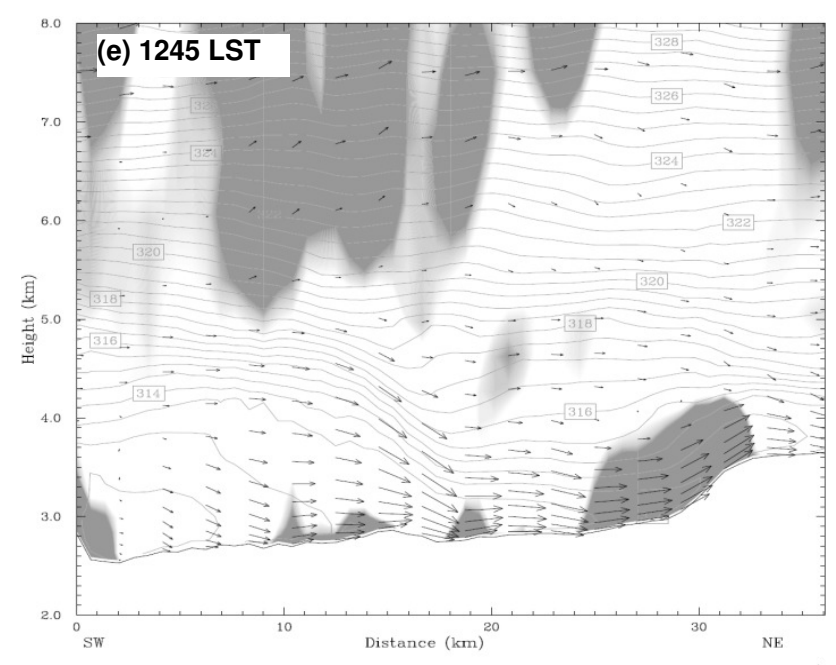

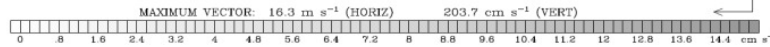

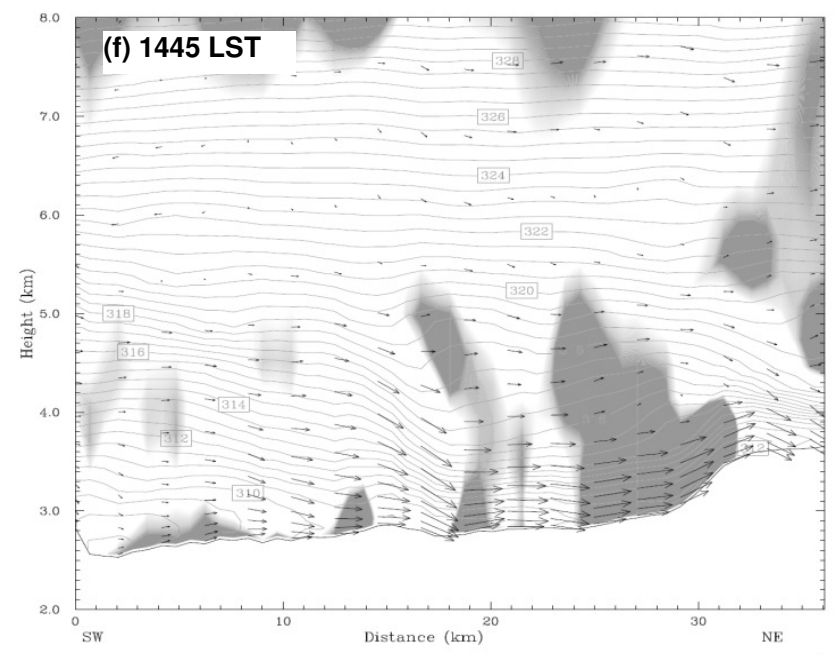

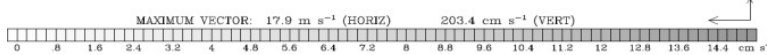

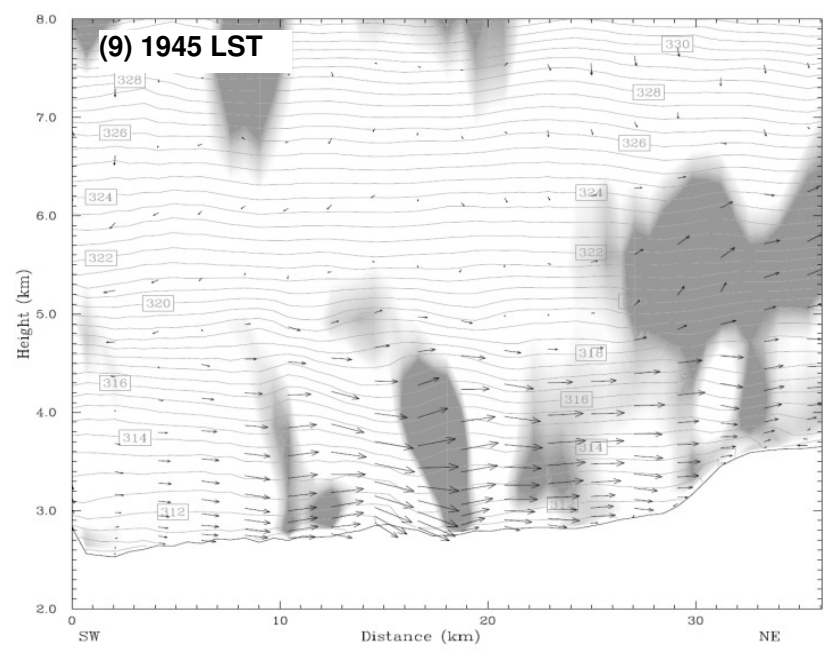

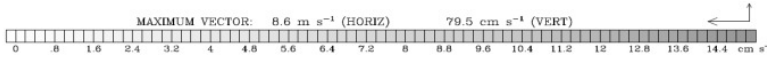

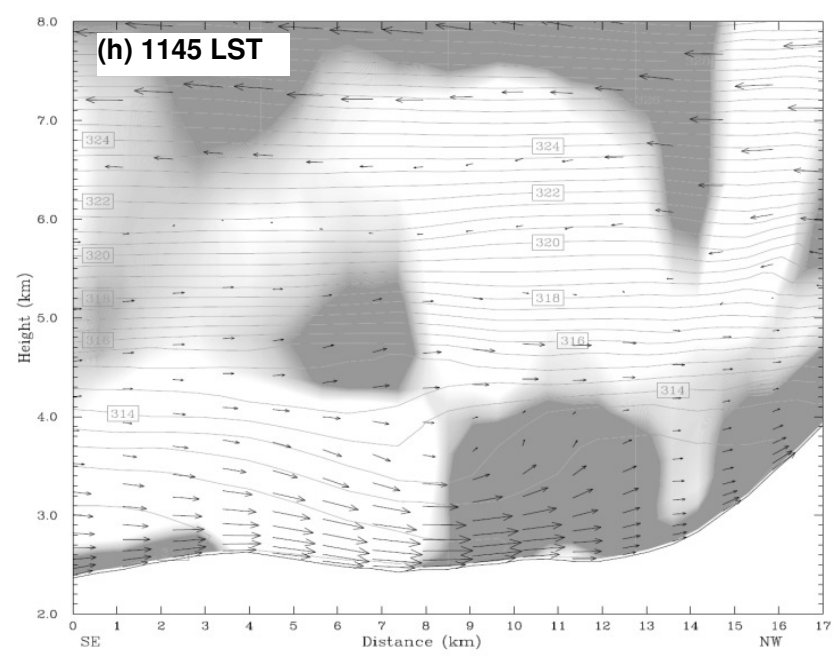

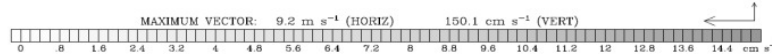




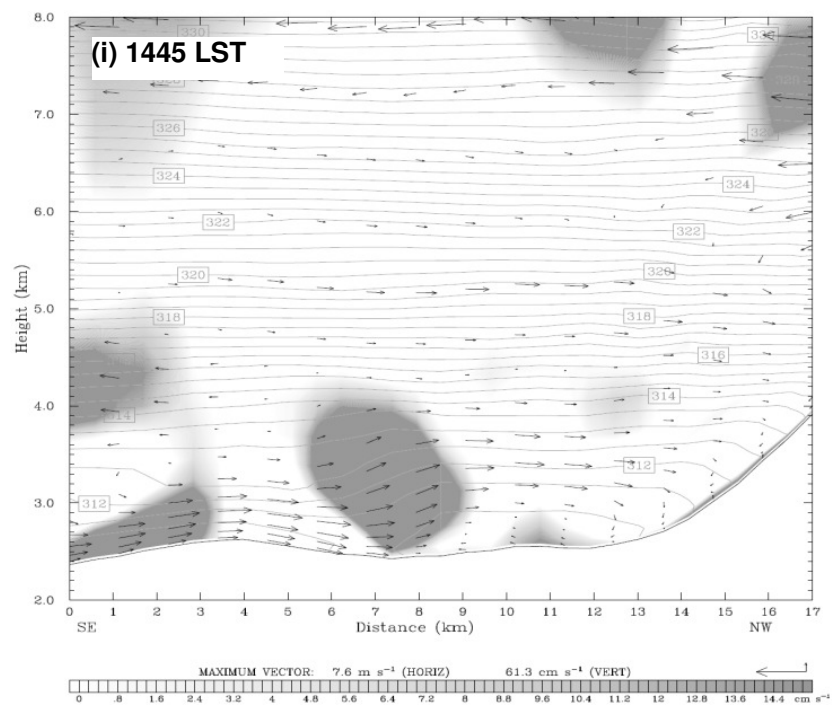

Fig. 6. Cross-sectional distribution of potential temperature, horizontal and vertical winds along the line $A-B(a-g)$ and along the line $C-D(h-i)$ in Fig. $5 g$ over the Kali Gandaki Valley and Jomsom Airport on 16 May 2012.

The upvalley wind structure close to the noontime and in the afternoon strongly suggests that a hydraulic jump like flow accompanied with massive scale vertical wind speed and gravity wave excitations might have been occurring over the Jomsom-Kagbeni areas (Fig. 6f). The hydraulic jump like flow subsides by 1945 LST (Fig. $6 \mathrm{~g}$ ) and the near surface upvalley wind vanishes by 2045 LST gradually leading to the situation descried earlier for late night and early morning period.

The night and morning time flow structure along the cross section $\mathrm{C}-\mathrm{D}$ (Fig. $5 \mathrm{~g}$ for location) capture nearly the same nature of drainage flow along the ling $\mathrm{A}-\mathrm{B}$ but its intensity is relatively higher. Interestingly, over this area no wind layer remains aloft the drainage flow. It is important to note that in the late morning time an intense southeasterly upvalley wind flows up along the valley from Ghasa and Lete that turns southeasterly possibly guided by the $\mathrm{C}$-shaped curbing of the gorge at Tukuche. In so doing, it creates a massive vertical wind at the corner of the valley (Fig. 6h). The depression of potential temperature above the upvalley wind layer and flow pattern again suggest that the flow over Tukuche area is supercritical. This particular nature of flow may continue until the afternoon time but in the late afternoon the upvalley wind lifts up over the Tukuche area and continues to feed over Marpha area keeping the Tukuche area calm (Fig. 6i).

\section{Aviation hazard over Jomsom airport}

The diurnal variation of wind over the Kali Gandaki River Valley appears to be highly hazardous for aviation activities beginning from late morning to evening. Very intense upvalley wind prevails along the gorge through which only a small aircraft can hardly make its way to Jomsom Airport. The upvalley wind also appears to make hydraulic jump like flow over the Jomsom Airport and is accompanied with wave excitations. Even during the morning time, the local flow system of the valley does not look favorable since a moderately gentle drainage wind prevails during the period with opposite flow aloft.

A light aircraft of Nepal Airlines crashed at the bank of Kali Gandikai River in the process of takeoff at about 0930 LST on 16 May 2012 (Fig. 2c). It is of the interest to explore the possible reasons that might have led to this particular disaster during the period of late morning as the local flows during the period could be responsible for this crashing.

During the period of 0845 and 0945 LST on the day (see Figs. 5c-d \& 6c-d) significant subsidence appears to occur over the Jomsom Airport area causing a downslope wind over the surfaces of the airport. Since, wind characteristics measured at the airport were not available for us to incorporate in the discussion and the authors are not aware of the very details history of the incidence, it was not possible to derive definite conclusions.

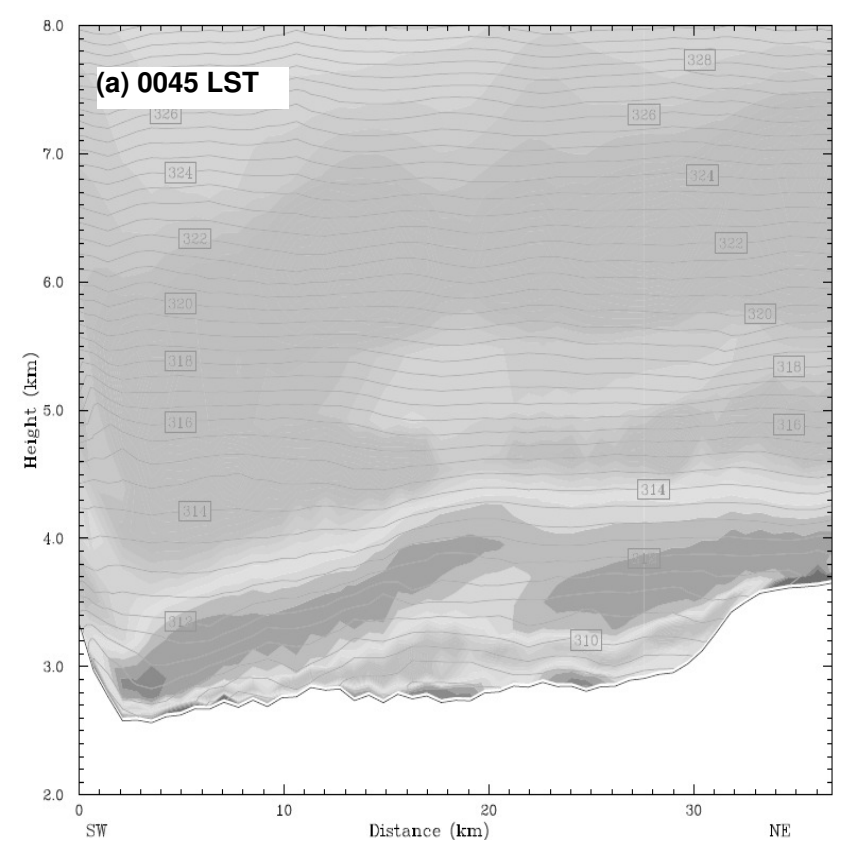



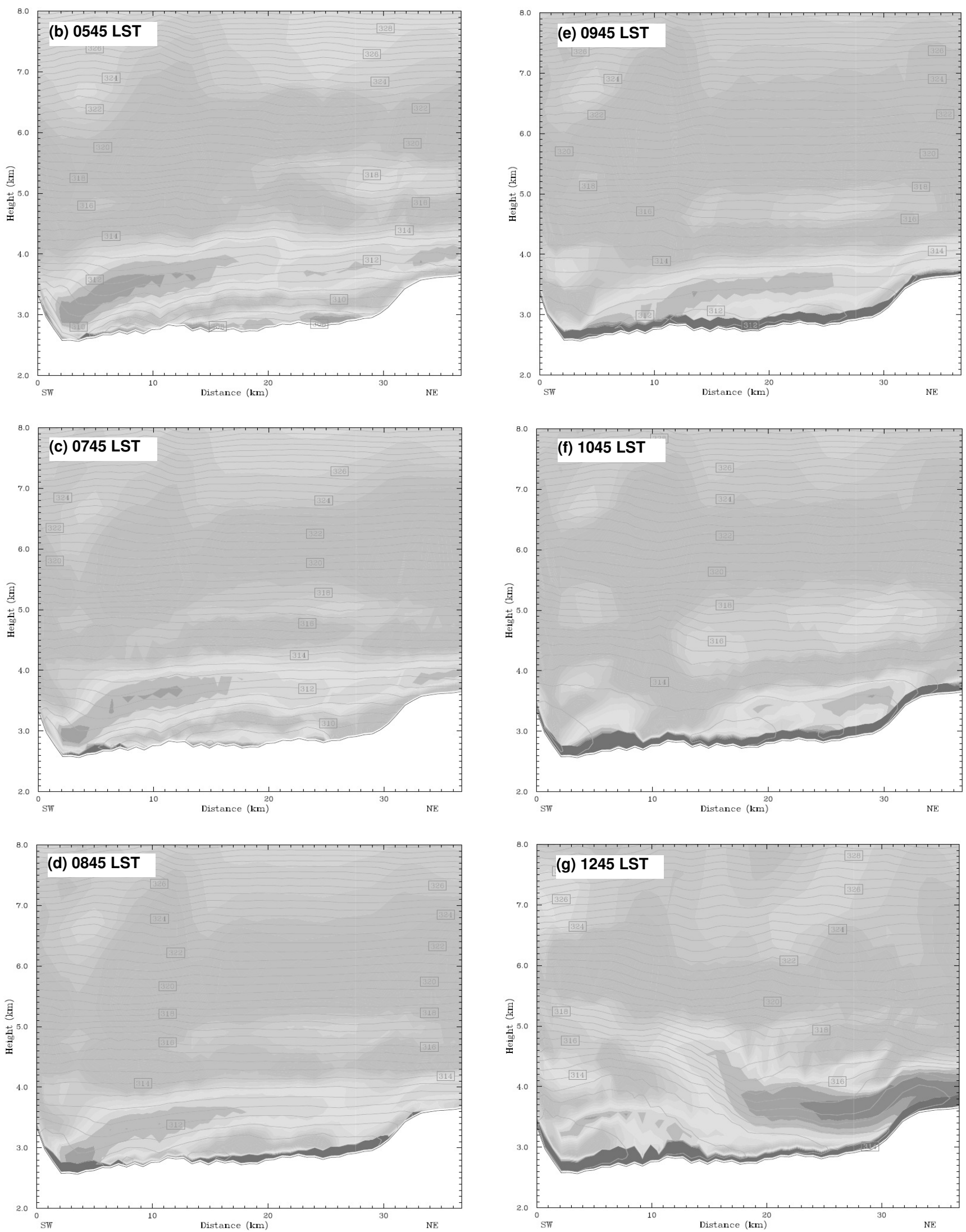

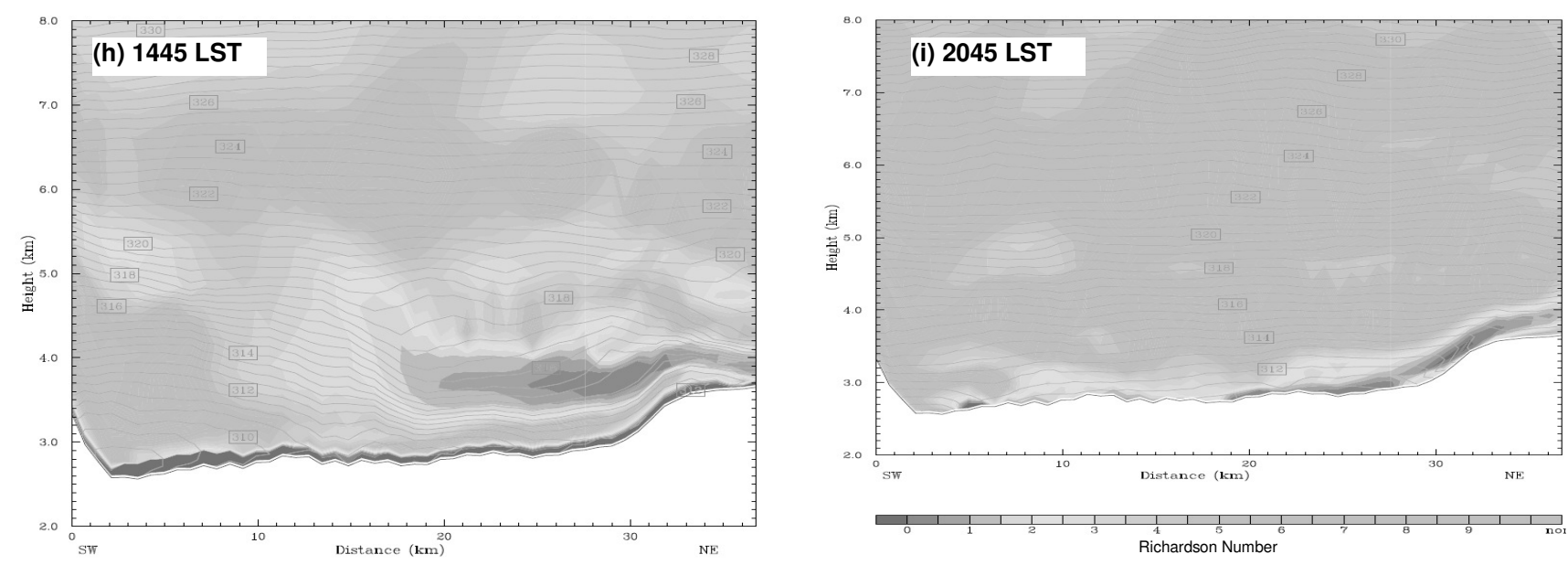

Fig. 7. Cross-sectional distributions of Richardson number along the line A-B (a-g) in Fig. $5 \mathrm{~g}$ over the Kali Gandaki Valley and Jomsom Airport on 16 May 2012.

However, it can be said that the subsidence flow and downslope wind over the runway might have caused significant decrease in lifting capacity of the plane. The complex combination of the subsidence flow from wind layer about couple of hundred meters above the surface, reverse flow and thus developed so-called low-level turbulence in the immediate atmosphere over the runway might have leaded the aircraft to crash on the bank of the Kali Gandaki River soon its takeoff.

Furthermore, the wind flow pattern over the surface and aloft during the period appears highly favorable to generate sufficient windshear - one of the major hazards for aviation especially when operating at low levels. Windshear is considered to be the second most important sources of turbulence. It is well known that light aircraft are prone to be buffeted, and are significantly affected even by light turbulence.

Fig. 7 shows the evolution of turbulence evaluated via reference to the Richardson number over the Jomsom Airport during the day of 16 May 2012. It is believed that values of Richardson number between 0.25 and 1.0 allow the persistence of turbulence, whereas values greater than 1 will tend to cause any existing turbulence to subside. Judging from the values of the Richardson number distribution along the cross section of the line $\mathrm{C}-\mathrm{D}$ (Fig. $5 \mathrm{~g}$ for orientation of the line), it can be said the boundary layer over the Jomsom Airport should have been strongly turbulent during the aircraft crashing time since the Richardson number is less than or about zero over the airport area.

\section{CONCLUSIONS}

Present study on the aviation hazards along the Kali Gandaki Valley and over the Jomsom Airport has indicated that there can be unexpected adverse meteorological activities that may lead to severe aircraft crashing. However, it should be noted that a single case study is obviously not sufficient to derive definite conclusions.
Further in-depth numerical simulations taking number of case studies over Jomsom Airport and beyond incorporating the physical parameters, conditions, and capacity of the aircraft, the experience and views of pilots/passengers survived in the crash as well as the report of the probe commission of the crash have been planned for near future. Present findings have laid a strong basis to examine meteorological hazards for aviation activities over the highly complex terrain of Himalayas as well as throw lights on the need of documenting meteorological activities over the air route and airports that could possibly prevail. Future researches would be directed towards the real-time predictions of meteorological events over the airports and air routes for improved flight safety and comfort in Nepal.

\section{ACKNOWLEDGEMENTS}

This research was partially funded by University Grants Commission, Nepal. Authors are thankful to the Alternative Energy Promotion Center, Nepal Government for providing observation data for comparison.

\section{REFERENCES}

Egger, J., Bajrachaya, S., Egger, U., Heinrich, R., Reuder, J., Shakya, P. , Wendt, H., and Wirth, V., 2000. Diurnal winds in the Himalayan Kali Gandaki valley. Part I: Observations. Mon. Wea. Rev. 12: 1106-1122.

Egger, J., Bajracharya, S., Heinrich, R., Kolb, P., Lammlein, S., Mech, M. , Reuder, J. , Schaper, W. , Sakya, P. , Schween, J., and Wendt, H., 2002. Dirunal Winds in the Himalayan Kali Gandaki Valley. Part III: Remotely Piloted Aircraft Soundings. Mon. Wea. Rev. 130: 20422058.

Skamarock, W. C., Klemp, J. B., Dudhia, J., Gill, D. O., Barker, D. M., Wang, W., and Powers, J. G., 2005. A description of the advanced research WRF NCAR/TN468+STR, 88 pp.

Zängl, G., Egger, J. and Wirth, V. 2001. Diurnal winds in the Himalayan Kali Gandaki valley. Part II: Modeling. Mon. Wea. Rev. 12: 1062-1078. 